\section{Timing of Injection of Pregnant Mare's Serum for the Anoestrous Breeding of Ewes}

WE have been able to induce fertile oestrus in anoestrous Romney ewes by placing a sponge impregnated with progestagen* in the vagina and injecting a follicle stimulating dose of 1,000 r.U. of pregnant mare's serum (PMS) on the day of removal of the sponge ${ }^{1}$. There was, however, no significant increase in the percentage of multiple births with this treatment.

We have since been able to increase the conception rate and the percentage of multiple foetuses by injecting PMS 2 days before removing the vaginal sponge.

The experimental animals used were 1507 year old Romney ewes which had lambed during Juno, July and August, 1965, and which were run with ten crayonharnessed Southdown rams on pasture at Hamilton, New Zealand, from December 17, 1965, until May 15, 1966.

Four groups of thirty ewes (groups 1-4) were treated with sponges and PMS from December 17, 1965, and one group of thirty ewes (group 5) was not treated and served as a control group (Table 1). The ewes were examined each day at 9 a.m. to determine whether they had mated.

Table 2 compares the degree of synchronization as indicated by the number of ewes in oestrus on day 14that is, those which were counted at 9 a.m. on day 15 .

Tho number of ewes in oestrus on day 14 was significantly higher for the groups treated with PMS on day 11 compared with those treated on day $13(P<0.01)$.

On day 66, fifteen ewes selected at random from each group were killed and the number of foetuses determined. Table 3 presents the results of this examination. Of the fifteen untreated ewes slaughtered, pregnancy had not been established long enough in all ewes to determine the number of foetuses present.

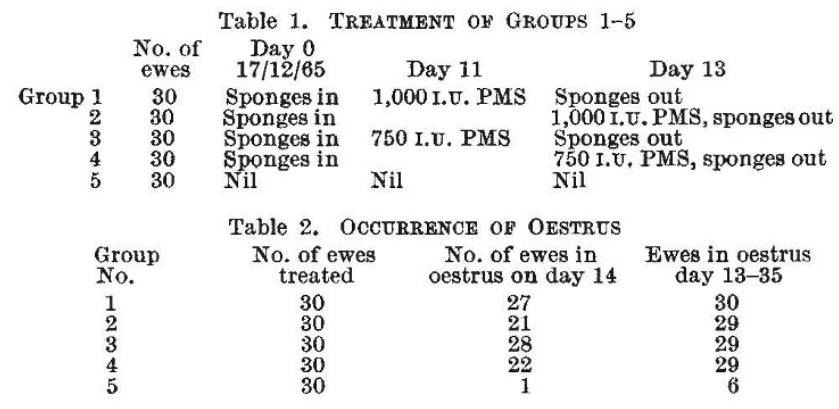

Table 3. Number of Corpora lutea and Viable Fottuses present on DAY 66 Mean Mean

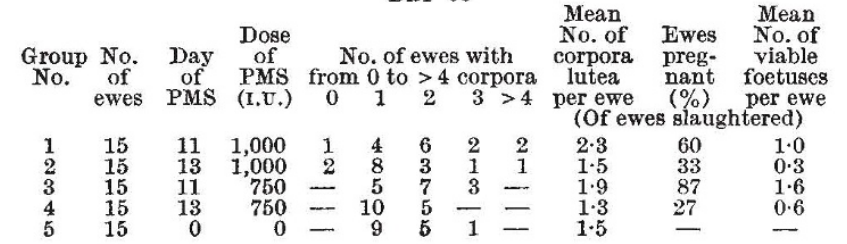

The number of corpora lutea, the percentage of ewes pregnant and the number of viable footuses are all significantly greater for day 11 compared with day 13 $(P<0.05)$. The dose of PMS had no significant effect on these traits.

The administration of PMS 2 days before removing the sponges resulted in better synchronization of oestrus with an associated increase in the percontage of pregnancies and foetuses.

Edgar and Ronaldson ${ }^{2}$ reported that the concentration of progesterone in ovarian venous blood falls dramatically on the sixteenth day of the oestrous cycle, when follicle development is already well advanced, and this fall in the concentration of progesterone is rapidly followed by oestrus and ovulation.

* 6-Methyl-17-acetoxy progesterone ('Repromap', The Upjohn Company).
The injection of PMS while progestagen is still being absorbed from the vaginal sponge, followed after 2 days by the withdrawal of the sponge, appears to simulate the situation in the normal oestrous cycle.

Note added in proof. Lambing data for the remaining fifteen ewes in each group have now been obtained. They agree with the results obtained at slaughtor, except that the percentage of ewes pregnant in group 3 averages 67 per cent.

E. M. ROBERTS

University of New South Wales, Kensington.

\section{G. EDGAR}

Ruakura Agricultural Research Centre, Hamilton, Now Zealand.

1 Roberts, E. M., and Edgar, D. G., J. Reprod. and Fertil. (in the press).

' Edgar, D. G., and Ronaldson, J. W., J. Endocrinol., 16, 378 (1957).

\section{Transport of Eggs from the Fallopian Tube to the Uterus as a Function of Oestrogen}

IT takes about 3 to 4 days for eggs to reach the uterus after oestrus in most mammals, regardless of the length of the tubes ${ }^{1}$. In the rabbit the transport of eggs through the ampulla to the isthmus of the tube takes only a few minutes ${ }^{2,3}$, but 3-4 days ${ }^{4-6}$ are required for transport to the uterus. The eggs do not seem to be transported at the same speed during their passage through the whole tube, but they stop in the isthmus or in the uterine tubal junction and await some action of the tube which will transport them into the uterus.

Progesterone secreted from the newly formed corpora lutea is apparently the active agent. Sevoral facts have been reported concerning the transport of eggs to the uterus: $(a)$ it occurs when the corpus luteum is in "full bloom" 1,7 ; $(b)$ it is accelerated in the rabbit on the fourth day of pseudopregnancy ${ }^{8}$, and by administration of progesterone after mating ${ }^{9,10}$; (c) the rapid transport of eggs in the opossum $(24 \mathrm{~h})$ is due to the large number of corpora lutea produced at each ovulation ${ }^{1}$; and $(d)$ egg transport is accelerated in superovulated domestic animals ${ }^{11-14}$. Oestrogen, however, has been reported to block the tube so that the eggs are "trapped" there ${ }^{10,15-18}$. The transport of eggs can be slowed down in superovulated cows by application of oestrogen ${ }^{19}$.

Recent work on the transport and development of rabbit eggs has shown that transport is speeded up and caused to degenerate by the administration of oestrogen after insemination and ovulation ${ }^{6,20}$ and also by treatment with progesterone for 3 days before ovulation ${ }^{21}$. Transplantation of eggs into the ampulla of the Fallopian tubes of non-ovulated oestrous rabbits clearly demonstrates that the transport of eggs from the tube to the uterus is speeded up by oestrogen, while progesterone counteracts the oestrogenic effect and slows down the egg transport for a few days.

About fifteen fertilized eggs (at the pronuclear to the two cell stage) recovered from superovulated rabbits 1 day after insemination were transplanted ${ }^{22}$ into the ampulla of the left tube of groups of oestrous rabbits. These recipient rabbits were fed either with $0.1 \mathrm{mg}$ ethinyl oestradiol/rabbit for 2 days immediately before transfer and 1 day after transfer, or with $2 \mathrm{mg}$ medroxyprogesterone acetate/rabbit for 3 days before or 2 days after transplantation. They were killed at various times aftor transplantation and their left tubes, uterine horns and vaginae were flushed with saline to recover the eggs. Sevoral trends emorge from the data presented in Table 1. (a) In the control animals 44 per cent of the eggs reachod the uterus $41 \mathrm{~h}$ after transfer. This is faster than in the untreated, mated and ovulated rabbits with newly formed corpora lutea, in which no eggs reached the uterus $48 \mathrm{~h}$ after insemination, or $36 \mathrm{~h}$ after ovulation ${ }^{6}$. This shows that in the oestrous rabbit ondogenous oestrogen is active 